\title{
Study on the Socialization Function of College Student Associations and Its Strengthening Path
}

\author{
Juan Liu \\ Zhengzhou University of Industry Technology, Zhengzhou, Henan, 451150
}

Keywords: Student society; socialization; function; strengthening path

\begin{abstract}
Socialization is a unique behavior of human beings. The process of socialization refers to the process of transformation from natural persons to social people. Everyone must undergo a process of socialization in order to achieve friendly exchanges with others and to be perfected under the constraints of social norms. College students are a special group. In the process of participating in higher education, they can experience some simple socialization processes through activities such as study and practice. Participating in colleges and universities is a major way for college students to socialize. Although the entire socialization process cannot be completed in colleges and universities, the stage of college education has a crucial impact on the socialization of college students. Based on this, this paper mainly discusses the related issues of college student associations and college students' socialization.
\end{abstract}

\section{Introduction}

With the vigorous development of China's higher education, the number of fast-growing graduates has also brought tremendous social pressure, and it has also exacerbated the employment pressure of college students. In the modern social environment, college students must have a solid theoretical foundation in order to obtain good employment opportunities. They also need to have certain practical and practical skills. They need to have good psychological quality, sound personality and noble moral sentiments. It is also a new requirement for the socialization of college students. College associations are social groups that college students can participate in in colleges and universities. They have an important impact on the study, life and employment of college students. They can also play a correct guiding role in the socialization process of college students and help promote the healthy development of college students' physical and mental health. .

\section{The meaning of college students' socialization}

The process of socialization of college students is a process of change and adaptation of psychological roles. "When college students enter the society, they must adapt to the social and cultural environment and assume different social roles. Therefore, they need to have strong self-regulation ability to adapt to the transformation between different roles and environments in order to adapt to future social development." [1] The group of college students is in a period of rapid growth in both body and mind. They are in the initial establishment period in terms of outlook on life, values and world outlook, and the value guidance in this period has an important influence on the study and work after the university birthday. . On the one hand, when entering the university stage, without the constraints of parents and teachers, college students must learn to self-discipline and self-management, which will greatly enhance the subjective initiative of college students; on the other hand, college students begin to contact the society and reach out to society. People of all shapes and sizes are exposed to all kinds of information, so the cultivation of values at the university level is very important. From the perspective of the development of college students' socialization, it involves a lot of content and stages, including the following aspects: First, help college students develop good character and habits, whether in learning, living, or socializing. They can all realize the influence of their own personality and behavior on other people and society, strengthen the sense of responsibility of college students, and transform the independent 
consciousness of college students into a collective consciousness, and enter the initial stage of socialization. Secondly, it is necessary to improve the college students. The social adaptability must be continuously strengthened in terms of physical quality and psychological quality. While fully respecting the individual characteristics of each student, "strengthen the correct understanding of the role of college students in self-social roles and lay a good foundation for entering the society. ". [2]

\section{The socialization function of college student associations}

The student association is an important form in the current campus culture construction, and is deeply loved by students. The socialization process of college students is a long and systematic process. By participating in college associations, it can effectively promote the socialization process of college students. College students have laid a good foundation for entering the society." [3] The influence of college student associations on the socialization of college students is mainly reflected in:

College student associations are a special form of association, "taking college campus culture as the background and college students as the organizers and main members of the community." [4] Therefore, the influence of student associations on the moral socialization of college students is the most significant. First of all, college student associations are peer groups with convergence values, so the atmosphere they form in the community has obvious openness and democracy. Under this environment, college students can form self-discipline ability to morality. Each student will consciously improve their moral cognition in the process of participating in the community activities, and close to the moral level of the whole society. Secondly, college students often participate in club activities, and the sense of collective honor will also be enhanced. When this kind of consciousness is reflected in the daily learning and life of students, they will participate in various social activities and realize self-worth in this process. Enhance the public participation awareness of college students.

The development of the activities of college student associations is inseparable from the guidance and assistance of the Communist Youth League organizations and administrative departments. Colleges and universities have always paid attention to the grasp and guidance of the political direction of student associations, and always adhere to the importance of Marxism-Leninism, Mao Zedong Thought, Deng Xiaoping Theory, etc. The ideological guidelines lead the healthy development of student associations. Therefore, many college student associations have obvious political characteristics. At the same time, many like-minded college students have also established different types of political organizations such as Deng Xiaoping Theory Research Association and Harmonious Society Research Association. This also shows that college student organizations are not only an important part of university campus culture, but also a socialist spirit. The important carrier of civilization construction, so college students can participate in student associations, which can enrich the channels of ideological and political education for college students, help college students to establish a correct outlook on life, world outlook and values, and strengthen the cultivation of ideological and moral quality of college students, and ensure the continuous socialization of college students. Adhere to the correct ideological orientation.

The development of college community activities has a very important impact on the socialization of college students' personality. First of all, participating in community activities can give full play to the advantages of college students. Whether it is language, singing or theory, students can find a platform that can play a skill, and promote the free development of college students' personality. Secondly, participating in college student club activities can strengthen college students. The main spirit, the main spirit is the core idea of individualized education for college students. The equal and harmonious communication atmosphere within the student association is the yearning and longing for each college student. Under this communication atmosphere, students can get more equality with other members. The opportunity of communication can not only improve the communication ability of college students, but also enable them to get a bigger Mazu work mentally, and it is also more conducive to helping college students to form self-respect and 
self-reliance. Finally, it can promote the enhancement of the main ability of college students, because college students participate in the student associations, taking into account their own interests, hobbies and abilities, and there is also a certain degree of competition among each student community, so in order to achieve the good development of their own associations Every group must fully exert its own abilities and spare no effort to contribute its own strength to the society. In this process, each member becomes the main body of the society, so the student's subject ability is more fully released and enhanced. .

College associations have an important influence on the cognition and understanding of college students on social roles. Student associations can realize the continuous improvement of college student associations and promote their socialization process by referring to and imitating the activities and organization of social associations. In this process, "college students have a more accurate understanding of their social role expectations". [5] At the same time, it can also help college students to broaden the depth and breadth of their social role recognition, which can eliminate the imprisonment of self-character positioning in college students' thinking, so that they can be more flexible and free in the process of participating in social activities. thought of. In addition, by participating in student associations, college students can accumulate experience in the process of participating in practical activities, and experience different role emotions, accumulate role-playing and correct experience of role conflicts, and prepare students for successful entry into society.

\section{The strengthening path of the socialization function of college student organizations}

College student associations play an important role in promoting the socialization of college students. Therefore, it is necessary to strengthen the guidance and management of college student associations to ensure their own scientific development, in order to give full play to their active guidance and promotion.

The members of the student association are all university students, and the university students who participate in the same society tend to be consistent in their outlook on life and values, so it is easy to "form a universally recognized and followed values orientation in the community". [6] Therefore, the first priority is to ensure the correct values orientation of the student community. Undergraduates' mentality is not mature enough. Under the influence of external environmental factors, values are likely to be biased and even develop in extreme directions. In addition to the impact on college students, it will also affect the overall value orientation of student organizations. The computer community is likely to develop into a "hacking community" due to the strong professional skills of some students, invading other people's computers, and even causing criminal behavior. Therefore, colleges and universities must adhere to the correct value orientation guidance for the student associations, and ensure the health and stability of the student associations in order to promote the socialization of the university students' health.

The management of student associations in colleges and universities is often managed by students of various departments, which improves the enthusiasm of college students to a certain extent, and can also exercise the organizational and management abilities of college students. However, in this process, "colleges and universities must always adhere to their leading role and always ensure that the colleges and universities have a clear management system and management structure" [7], through the coordination and communication with the party committee leaders and administrative departments of the university, in the student associations. The establishment of a clear management system in terms of registration, membership recruitment, development methods, and funding sources can ensure the orderly development of student club activities. In addition, it is necessary to clarify the status of student associations, "eliminate the constraints of traditional management systems on student associations" [8], and adopt positive encouragement and guidance methods to create a good institutional environment for the healthy development of student associations.

Hundreds of schools of thought and flowers are the development goals of college student associations. The influence of college student associations is actively developing in a diversified 
direction to meet the needs of college students, actively innovating in the form and content of associations, and advocating the establishment of public service organizations and academic research. At the same time, colleges and universities should give the student associations a certain amount of financial support, and "allow the student associations to go out of the campus and communicate and communicate with enterprises and social groups." [9] On the one hand, it can raise more funds for the activities of student clubs, on the other hand, it can also promote the sharing of resources and lay a richer social foundation for the development of student associations.

\section{Conclusion}

In summary, as an important part of college campus culture, student associations have an important impact on the socialization of college students. By participating in student associations, they can improve the self-education and self-management ability of college students while improving the knowledge system of college students. Especially in improving students' ideological and moral quality, there are other social activities that cannot be replaced. Therefore, in the process of building colleges and universities, we must pay attention to the needs of adapting to the socialized development of college students, give full play to the socialization function of student associations, guide and help college students to successfully complete the socialization process, and smoothly enter the society and find a suitable position. , get a good development prospects.

\section{References}

[1] Bao Min, Zhou Sumeng. On the Influence of College Student Associations on College Students' Socialization[J]. Examination Weekly, 2014, 08: 155.

[2] Chen Liang, Wang Yi. Analysis of College Students' Socialization Function on College Students' Association[J]. Science and Technology Information, 2009, 35: 167+221.

[3] Li Xiaoke. The Influence of College Sports Associations on Students' Socialization[J]. Journal of Shenyang College of Education, 2009, 04: 40-42.

[4] Wu Li, Yuan Shizhe. Analysis of the Influence of College Sports Associations on College Students' Socialization[J]. Contemporary Sports Science and Technology, 2015, 10:70+72.

[5] Zhang Lin. Research on the role of college student associations in the process of college students' socialization [D]. Hebei University, 2013.

[6] Shi Jiaying. Research on the Influence of College Student Associations on College Students' Socialization [D]. Shandong Normal University, 2013.

[7] Qu Xia. Research on the function of college student associations in the socialization of college students [D]. Xi'an University of Technology, 2011.

[8] Zhu Zhongxiang, Sun Jiawen. Research on the Relationship between College Student Associations and College Students' Socialization[J]. Journal of Guangdong Institute of Petrochemical Technology, 2011, 02: 37-39.

[9] Shi Caixia. College Students' Community in the Perspective of College Students' Political Socialization[J]. Journal of Suzhou University, 2010, 06: 74-76. 